\title{
Flu Shots vs. Natural Flu Remedies: What Works Better?
}

\section{Alex Tate*}

Imperial College London, South Kensington Campus, London, UK

\author{
Abstract \\ Flu season is upon us, and that means people are lining up for a flu shot and stocking up on vitamin C. But what's \\ the best way to keep the flu at bay-vaccination or natural remedies? You may be surprised at the answer.
}

Keywords: Flu shots; Natural flu remedies; Flu vaccine; Health

\section{What You Should Know about the Flu Vaccine}

You may be surprised to hear that the flu vaccine is not $100 \%$ effective. Perhaps in years past, you or someone you know has been vaccinated and still gotten sick. Each year the CDC conducts studies to determine how effective that years' batch of vaccines are. While vaccine effectiveness varies, recent studies show the vaccine reduces the risk of getting the flu by about $50 \%-60 \%$.

Overall effectiveness is based on the similarity or "match" between the flu viruses the flu vaccine is designed to protect against and the flu viruses spreading in the community. The better the match, the more effective that flu shot will be.

Also worth mentioning is the fact that the flu vaccine's effectiveness can vary among individuals. So while some people get the full 50\%-60\% coverage, some people might get less. This is determined by factors such as a person's age and their level of health.

Though the flu vaccine is not $100 \%$ effective, it is highly recommended everyone get their yearly shot for the following reasons:

- A flu shot can reduce the risk of flu-associated hospitalizations, including among young children and senior citizens.

- A 2014 study showed that flu vaccine reduced children's risk of flu-related pediatric intensive care unit (PICU) admission by 74\% during flu seasons between the years 2010 and 2012 .

- Another study published from 2016 showed that individuals 50 years and older who received a flu shot reduced their risk of hospitalization from flu complications by $57 \%$.

- Flu shots are an important preventative measure for people with chronic health conditions and are associated with lower rates of cardiac events among those with heart disease. They have also been shown to reduce hospitalizations with those suffering from diabetes (79\%) and chronic lung disease (52\%).

- Vaccination helps protect women during and after pregnancy. Getting vaccinated also protects the developing baby during pregnancy and for several months after the baby is born.

- Flu vaccination also may make your illness milder if you do get sick.

- Getting vaccinated yourself also protects people around you, including those who are more vulnerable to serious flu illness, like babies and young children, older people, and people with certain chronic health conditions.

\section{Sources}

\section{Natural flu remedies-which ones really work?}

As we've just discussed the flu vaccine is not $100 \%$ effective [1-3]. In a way the flu vaccine is a bit like a seatbelt - you should definitely wear one for your safety, but that doesn't mean there aren't other things drivers should do to remain safe while driving.

In combination with some natural remedies, the vaccine has a much better chance of keeping you and your family healthy this winter. Here are some traditional approaches to fighting the flu:

Kill germs: Unfortunately, during the winter season, most public spaces are crawling with germs and viruses. When just one person sneezes or coughs they essentially spray the virus out into the atmosphere and those little droplets could wind up in your respiratory system. At the very least, they'll land on door handles, communal pens and shopping carts, etc., and can stay alive for up to 8 hours. And, when you touch a germy surface or object and then rub your eyes, nose or mouth, those germs enter your body. So, wash your hands often avoid touching your face as much as possible. Also a good idea to carry an alcohol-based hand sanitizer when you can't get to a sink. Disinfectant wipes are also great for wiping surfaces and objects.

Support your immune system: Your immune system was created to keep you healthy. Unfortunately, too much stress and the typical modern diet does little to keep our immune systems working optimally.

Support your immune system by:

- Eating a diet rich in colorful produce and low in processed foods.

- Exercising at least 4 days a week.

- Getting 7 to 9 hours of sleep each night.

Stop smoking: You already know smoking is really bad for you and can increase your risk of cancer and heart disease, but did you know smokers are more likely to get the flu? Not only have studies found smokers get sick more often but when they do, symptoms seem to last longer and the chance of developing an infection increases.

*Corresponding author: Alex Tate, Science Communication Group Administrator Level 3, Sherfield Building, Imperial College London, South Kensington Campus, London SW7 2AZ, UK, Tel: +44 (0)20 7594 8753; E-mail: alextate07@gmail.com

Received August 26, 2017; Accepted September 19, 2017; Published September 25,2017

Citation: Tate A (2017) Flu Shots vs. Natural Flu Remedies: What Works Better? J Health Med Informat 8: 286. doi: 10.4172/2157-7420.1000286

Copyright: () 2017 Tate A. This is an open-access article distributed under the terms of the Creative Commons Attribution License, which permits unrestricted use, distribution, and reproduction in any medium, provided the original author and source are credited. 
Look, one more reason to talk to your doctor about ways you can quit.

Flu shots or natural remedies - which are better? The truth is they work best when used in combination. So, get your flu shot, kill those germs, support your immune system and stop smoking and stay healthy this winter.

\section{Author Biography}

Alex Tate is an expert marketer who specializes in promoting and growing physician practices. He currently works with Urgent_Way to help improve their online footprint and garner interest in their Urgent Care, Occupational Health and Health Services.

\section{References}

1. Belshe RB, Mendelman PM, Treanor R (1998) The efficacy of live attenuated, cold-adapted, trivalent, intranasal influenza virus vaccine in children. $\mathrm{N}$ Engl J Med 338: 1405-1412.

2. Benowitz I, Esposito DB, Gracey KD (2010) Influenza vaccine given to pregnant women reduces hospitalization due to influenza in their infants. Clin Infect Dis 51: 1355-1361.

3. Ciszewski A, Bilinska ZT, Brydak LB (2008) Influenza vaccination in secondary prevention from coronary ischaemic events in coronary artery disease: FLUCAD study. Eur Heart J 29: 1350-1358. 